\title{
Legislação Indigenista e Perspectivas para o Turismo em Terras Indígenas no Brasil ${ }^{1}$
}

\author{
Sandra Dalila Corbaria \\ Miguel Bahlb \\ Silvana do Rocio de Souzac
}

\section{Resumo}

0 turismo envolvendo comunidades indígenas vem sendo desenvolvido em diversas partes do mundo. No Brasil, há inúmeras iniciativas que, no entanto, não eram regulamentadas por conta de questões como a tutela do Estado, falta de consenso entre estudiosos, governo, entidades e comunidades sobre a importância da regulamentação, entre outras. No entanto, a legislação nacional não proibia explicitamente o turismo em territórios indígenas e, em diversos documentos, o Estado apontava a importância da autonomia e protagonismo indígena, inclusive em projetos sustentáveis de ecoturismo e etnoturismo; e, também ressaltava a necessidade da regulamentação desses segmentos. Em junho de 2015, o turismo em Terras Indígenas foi regulamentado, trazendo o debate sobre o turismo envolvendo comunidades indígenas a um novo patamar. Assim, este artigo, embasado em instrumentos legais e na literatura sobre o tema, aborda a legislação indigenista brasileira e as novas perspectivas para a atividade turística, o desenvolvimento econômico e autonomia desses povos. A pesquisa demonstrou que a regulamentação da atividade não contribui integralmente para a autonomia das comunidades, uma vez que se faz necessária a autorização da Fundação Nacional do Índio, que pode, inclusive, negá-la. Além disso, apesar de estar voltada ao princípio da precaução, a burocracia do processo dá margem à continuidade do turismo ilegal.

Palavras-chave: Legislação; Terras indígenas; Turismo; Brasil.

\section{Abstract}

Indigenous legislation and perspectives for tourism in indigenous lands in Brazil Tourism involving indigenous communities has been developed in various parts of the world. In Brazil, several initiatives, however, were not regulated due to issues such as State

1. Agradecemos ao CNPq por financiar, através de bolsa, parte dessa pesquisa. Também ao Grupo de Pesquisa Turismo e Sociedade, ao qual essa pesquisa está vinculada.

a. Doutoranda pelo Programa de Pós-Graduação em Meio Ambiente e Desenvolvimento (MADE) da Universidade Federal do Paraná (UFPR). Mestre em Turismo pelo Programa de Pós-Graduação em Turismo da UFPR. Bacharela em Turismo pela UFPR. Curitiba, Paraná, Brasil. E-mail: corbari91@ hotmail.com

b. Estágio pós-doutoral desenvolvido na Universidade de Girona (Espanha). Mestre e Doutor em Turismo em Ciências da Comunicação pela Universidade de São Paulo (USP). Graduado em Turismo e Licenciado em Geografia e em Estudos Sociais pela Universidade Federal do Paraná (UFPR). Professor do Departamento de Turismo da UFPR no curso de Graduação em Turismo e nos programas de Mestrado em Turismo e Mestrado e Doutorado em Geografia. Curitiba, Paraná, Brasil. E-mail:migbahl@ufpr.br

c. Doutora em Geografia pela Universidade Federal do Paraná (UFPR). Mestre em Educação pela Universidade Tuiuti do Paraná (UTP). Graduada em Turismo pela Universidade Federal do Paraná (UFPR). Professora do Departamento de Turismo da UFPR no curso de Graduação em Turismo e no Programa de Mestrado em Turismo. Curitiba, Paraná, Brasil. E-mail: silvanasouza.tur@gmail.com 
jurisdiction, lack of consensus among scholars, government entities and communities on the importance of regulation, among others. However, the national legislation did not explicitly forbid tourism in indigenous territories, and in various documents, the State pointed the importance of indigenous autonomy and leadership, including in sustainable projects of ecotourism and ethnotourism; as well as highlighted the need for regulating these segments. In June 2015, tourism in Indigenous Lands was regulated, taking the debate on tourism involving indigenous communities to a new level. Therefore, this article, based on legal instruments and on the literature on the subject, addresses the Brazilian indigenous legislation and the new prospects for touristic activities, economic development and autonomy of these peoples. The research demonstrated that the regulation of the activity does not fully contribute to the autonomy of the communities, since it demands an authorization from the Brazilian National Indigenous Foundation, which may even deny it. In addition, despite being guided by the principle of precaution, the bureaucracy of the process allows for the continuity of illegal tourism.

Keywords: Legislation; Indigenous Lands; Tourism; Brazil.

\section{Resumen}

\section{Legislación indigenista y perspectivas para el turismo en Tierras Indígenas en Brasil}

El turismo desarrollado en comunidades indígenas se ha practicado en diversas partes del mundo. En Brasil, hay numerosas iniciativas que, sin embargo, no están reguladas debido a cuestiones como la tutela del Estado, la falta de consenso entre los académicos, agencias gubernamentales y las comunidades sobre la importancia de la regulación del turismo, entre otros. No obstante, la legislación no prohibía explícitamente el turismo en las zonas indígenas. En varios documentos, el Estado señaló la importancia de la autonomía y el liderazgo indígena, incluyendo proyectos en ecoturismo sostenible y etnoturismo, enfatizando también la necesidad de una regulación de estos segmentos. En junio de 2015, el turismo en Tierras Indígenas (TIs) fue regulado, haciendo con que el debate sobre el asunto llegase a un nuevo nivel. En este artículo, se discute la legislación indígena brasileña y nuevas perspectivas para el turismo, el desarrollo económico y la autonomía de estos pueblos. La investigación ha demostrado que la regulación de la actividad no contribuye plenamente a la autonomía de las comunidades, ya que es necesaria la autorización de la Fundação Nacional do Índio (FUNAI), que podrá no autorizar la iniciativa. Además, aunque esté centrada en el principio de precaución, la burocracia del proceso da lugar a la continuación del turismo ilegal.

Palabras clave: Legislación; Tierras Indígenas; Turismo; Brasil.

\section{INTRODUÇÃo}

No Brasil, há décadas são propostas diversas iniciativas de turismo envolvendo comunidades indígenas - que, no entanto, não eram regulamentadas. Diversas questões vinham inibindo a regulamentação da atividade turística em Terras Indígenas (TI). Entre elas está o fato de serem os indígenas tutelados pelo Estado, por meio da Fundação Nacional do Índio (Funai), e a obrigatoriedade de quaisquer atividades desenvolvidas passar pelo crivo dessa instituição. Além disso, as TI pertencem à União, e a entrada nesses territórios é (ou deveria ser, conforme a legislação vigente) fiscalizada, sendo que a Funai não permite a entrada de pessoas estranhas às comunidades para qualquer fim sem sua prévia autorização ou das lideranças indígenas. Igualmente, a falta de consenso entre pesquisadores, 
governo, entidades e comunidades sobre a importância da regulamentação e de como ela deveria ser feita está entre os fatores que dificultaram a regulamentação dessa atividade turística.

No entanto, a legislação nacional não proibia explicitamente tal prática, diversos instrumentos legais vinham abordando, inclusive, a necessidade do desenvolvimento econômico e turístico nessas comunidades, além do fortalecimento da autonomia indígena sobre seu modo de vida e subsistência. A legislação brasileira afirma que: é de responsabilidade da União, estados e municípios, bem como dos órgãos das respectivas administrações indiretas, proporcionar aos indígenas meios para seu desenvolvimento, assegurar a livre escolha dos seus meios de vida e subsistência e contribuir para a eliminação das desigualdades socioeconômicas; é importante que os indígenas assumam esse controle e sejam protagonistas, inclusive em projetos sustentáveis de ecoturismo e etnoturismo; e, também, a necessidade da regulamentação desses segmentos (BRASIL, 1973; 2004; 2012a; 2012b).

Ainda que fosse confirmada pelos instrumentos legais a necessidade de dar autonomia aos povos indígenas, o turismo não era regulamentado até junho de 2015, quando entrou em vigor a Instrução Normativa 3/2015, da Funai, a qual regulamenta e estabelece normas para a visitação em TI para fins turísticos.

Nesse sentido, esta pesquisa, embasada em instrumentos legais, dissertações e teses, teve como objetivo abordar a temática e promover uma reflexão sobre a atual realidade do turismo envolvendo comunidades indígenas no Brasil. A seguir, apresenta-se uma breve abordagem sobre os indígenas, TI, legislação nacional e o entrave ao turismo, além da nova realidade e possibilidades oriundas da regulamentação estabelecida pela Instrução Normativa 3/2015. Por fim, apresentam-se as considerações finais.

\section{ABORDAGEM SUCINTA SOBRE INDÍGENAS, TERRAS INDÍGENAS E TERRITÓRIOS}

Ao abordar o aqui denominado "turismo em territórios indígenas", considerou-se necessário, primeiramente, tratar sobre algumas questões referentes a esses povos. Baseando-se no "Estudo do problema de discriminação contra as populações indígenas” (COBO, 1981), na Convenção 169 da Organização Internacional do Trabalho (OIT) sobre os Povos Indígenas e Tribais de 1989 (OIT, 1989) e no Documento de Trabalho do Grupo de Trabalho sobre Populações Indígenas da Organização das Nações Unidas (ONU, 1996), pode-se considerar, em âmbito global, que as populações indígenas são povos tribais que descendem de populações que habitavam um território nacional ou uma região geográfica na época das conquistas, de colonização ou do estabelecimento das fronteiras estatais atuais. Além disso, segundo esses mesmos estudos, os indígenas representam grupos: não dominantes da sociedade que tiveram experiências de submissão, marginalização, expropriação, exclusão ou discriminação, independentemente de essas condições persistirem ou não; e que sejam conscientes de sua identidade, sendo ela reconhecida por outros grupos ou por autoridades estatais, distinguindo-se da sociedade nacional por conta de suas condições sociais, culturais, econômicas e políticas, estando regidos total ou 
parcialmente por seus próprios costumes, tradições, ou por uma legislação especial, além de ter determinação de preservar, desenvolver e transmitir seus territórios ancestrais e sua identidade étnica para gerações futuras, contando com perpetuação voluntária da distinção cultural.

O antropólogo brasileiro Darcy Ribeiro (1957) compreendia os indígenas como a parcela da população que não se adaptava à sociedade em geral. Em princípio, não se concorda com tal afirmação, pois acredita-se que a sociedade não indígena também deveria adaptar-se às culturas indígenas. No entanto, entende-se por adequada a caracterização que esse autor faz do indígena como todo aquele que se reconhece como membro de uma comunidade pré-colombiana, motivado por costumes, hábitos e lealdade a uma tradição pré-colombiana (RIBEIRO, 1957). Assim, apesar da utilização generalizada, o termo tem designação geográfica para as Américas, identidade essa que foi atribuída por Cristóvão Colombo ao acreditar ter chegado à Índia (CALEFFI, 2003; LUCIANO, 2006). Nesta pesquisa adotou-se o termo "indígena" a partir dessa visão.

Diegues (2001) explica haver confusão em relação ao termo "indígena" (em inglês "indigenous"). Segundo esse autor, o termo "indigenous", utilizado em diversos documentos oficiais internacionais (como do Banco Mundial e da ONU), não significa que esteja referindo-se, necessariamente, aos indígenas no sentido étnico e tribal, já que alude também a povos nativos. No entanto, esse termo foi baseado principalmente nas condições de vida dos povos indígenas amazônicos, ou seja, da América do Sul.

Outra discussão pertinente a este trabalho diz respeito ao termo "turismo em terras indígenas", utilizado por diferentes autores. No caso do Brasil, grande parte dos indígenas vive em TI, área delimitada pelo Estado. As TI são classificadas, com base no Estatuto do Índio (BRASIL, 1973), na Constituição Federal (BRASIL, 1988) e no Decreto no 1.775 (BRASIL, 1996), em: Terras Indígenas Tradicionalmente Ocupadas (direito originário dos povos indígenas), Reservas Indígenas (terras doadas por terceiros, adquiridas ou desapropriadas pela União, para posse permanente dos povos indígenas), Terras Dominiais (propriedade das comunidades indígenas oriundas de qualquer forma de aquisição) e Interditadas (áreas interditadas pela Funai, para proteção dos povos e grupos indígenas isolados).

Posto isso, considera-se mais adequado utilizar o termo "turismo em territórios indígenas", uma vez que nem todas as comunidades indígenas estão inseridas em alguma TI. No entanto, para vias legais do turismo, costuma-se utilizar o conceito de Terra Indígena, por ser uma delimitação do Estado, deixando de lado outros territórios ocupados por indígenas, como aldeias não homologadas e comunidades urbanas.

Iniciativas de turismo envolvendo comunidades originárias estão sendo desenvolvidas em um vasto número de países, como é o caso do Japão, do Canadá, da Austrália, da Nova Zelândia, da Rússia, do Nepal, da Tanzânia, do Chile, do México, da Argentina, do Peru, do Panamá e da Venezuela (JESUS, 2012; LAC, 2005; OLIVEIRA, 2006; PÉREZ GALÁN; ASENSIO, 2012; RYAN, 2002; RYAN; HUYTON, 2002). No Brasil, identificou-se haver menção a vários povos indígenas também desenvolvendo essa atividade, como é o caso dos Kayapó, no Pará e no Mato Grosso; dos Trumai e Waurá, no Mato Grosso; dos Marajoaras, no Pará; os Pataxó, na Bahia; dos Guarani M’bya, em São Paulo, Rio de Janeiro e Paraná; dos Tapeba e Jenipapo-Kanindé, no Ceará; dos Kaingang, no Paraná, em Santa Catarina e no Rio 
Grande do Sul; dos Krikati, Gavião, Canela Apaniekra e Canela Ramkokamekra, no Maranhão; dos Apinayé, Krahô e Karajá, no Tocantins; dos Terena, no Mato Grosso do Sul; dos Potyguara, na Paraíba; dos Sateré-Mawé, no Amazonas; entre vários outros (BAGGIO, 2007; CORBARI; BAHL; SOUZA, 2015; CORBARI; GOMES, BAHL, 2013; GRÜNEWALD, 1999; GUIMARÃES, 2006; JESUS, 2012; LAC, 2005; LACERDA, 2004; LUSTOSA, 2012; NEVES, 2012; NUNES, 2006; OLIVEIRA, 2006; SANTOS, 2010). No entanto, verificou-se cada uma das comunidades desenvolvendo o turismo a partir das suas peculiaridades.

Indaga-se sobre a possibilidade de que os impactos negativos que a atividade turística pode gerar nas comunidades indígenas fossem fatores limitantes na elaboração de uma política de turismo em comunidades indígenas. Tais impactos envolvem, por exemplo, a transformação dos indígenas em tourees a inserção de valores que não condizem com os valores de uma dada comunidade, como é o caso do uso de drogas por parte dos turistas, como ocorria nas comunidades Pataxó de Barra Velha, em Porto Seguro e Coroa Vermelha, em Santa Cruz de Cabrália, Bahia; despersonalização dos trabalhos artesanais dos Pataxó (GRÜNEWALD, 1999) e na aldeia Puiwa Poho, em Feliz Natal, Mato Grosso (NUNES, 2006); guias de turismo que não consultavam a comunidade visitada; pagamento - quando havia - em bebida alcoólica, fumo ou comida, na região do Alto Rio Negro, Amazonas (FARIA, 2008); a espetacularização e a mudança de significado das técnicas artesanais, como pesca, preparo do beiju, produção de sal de aguapé, na aldeia Puiwa Poho; a mercantilização de rituais na aldeia Puiwa Poho (NUNES, 2006) e na aldeia Sahu-Apé, em Iranduba, Amazonas (SANTOS, 2010).

Embora esses aspectos sejam motivo de preocupação entre diversos pesquisadores, comunidades e entidades, não se pode negar que o desenvolvimento turístico também pode trazer benefícios às comunidades, como a geração de renda, principalmente para os jovens (GRÜNEWALD, 1999; NEVES, 2012), a valorização da prática artesanal pela comercialização, como ocorreu com os Kaingang da TI de Iraí (LAC, 2005), o fortalecimento da identidade étnica e tradições (LAC, 2005; SANTOS, 2010), conscientização dos não indígenas, principalmente no que diz respeito às problemáticas territoriais (LAC, 2005), a afirmação territorial, como ocorreu com os Jenipapo-Kanindé, em Aquiraz, Ceará, ao implantarem o turismo comunitário (LUSTOSA, 2012); melhora na qualidade de vida individual e diminuição da probabilidade de êxodo (BRANDÃO, 2012), entre vários outros aspectos positivos.

Assim como qualquer atividade econômica, o turismo se caracteriza como uma "via de mão dupla", no sentido de ser um potencial gerador de impactos negativos ou positivos, dependendo de cada caso específico e modo de gestão. No entanto, constatou-se que não havia um consenso entre pesquisadores, governo, entidades e comunidades, no Brasil, sobre as possibilidades e benefícios da implantação e regulamentação da atividade turística em territórios indígenas e sobre outras questões inerentes, sendo principais as legais, abordadas a seguir.

2. A denominação "touree" é dada por Van den Berghe e Keyes (1984) ao nativo como um performer, que modificou seu comportamento para tornar-se atrativo ao turista, fingindo sua arte, sua roupa, sua música, sua dança, sua religião, entre outros aspectos, para satisfazer a procura do turista por "autenticidade". 


\section{A LEgISLAÇÃo NACIONAL E O ENTRAVE AO TURISMO}

No Brasil, as questões referentes ao desenvolvimento da atividade turística em comunidades indígenas são margeadas - e limitadas - pela legislação nacional, que pode ser considerada ambígua, para não dizer incerta. Ocorre que a legislação não proíbe a existência da atividade; no entanto, também não a autoriza. No Estatuto do Índio (BRASIL, 1973) não há menção à atividade turística, exceto pelo fato de apontar ser crime a utilização de um sujeito ou comunidade indígena como objeto de propaganda turística. No entanto essa lei indica que:

Art. $2^{\circ}$ Cumpre à União, aos Estados e aos Municípios, bem como aos órgãos das respectivas administrações indiretas, nos limites de sua competência, para a proteção das comunidades indígenas e a preservação dos seus direitos:

[...] III - Respeitar, ao proporcionar aos índios meios para o seu desenvolvimento, as peculiaridades inerentes à sua condição;

IV - Assegurar aos índios a possibilidade de livre escolha dos seus meios de vida e subsistência. (BRASIL, 1973, grifo nosso)

Com isso, entende-se que cabe à União, estados e municípios respeitar a escolha das comunidades indígenas e contribuir para o seu desenvolvimento em qualquer âmbito, incluindo o econômico, no qual estaria estabelecida a atividade turística.

Já a Constituição Federal de 1988, no artigo 231, confere aos indígenas a posse e o usufruto exclusivo de suas terras:

$\S 1$ o - São terras tradicionalmente ocupadas pelos índios as por eles habitadas em caráter permanente, as utilizadas para suas atividades produtivas, as imprescindíveis à preservação dos recursos ambientais necessários a seu bem-estar e as necessárias à sua reprodução física e cultural, segundo seus usos, costumes e tradições. (BRASIL, 1988)

Entende-se, com essa declaração que o turismo poderia ser considerado uma dessas atividades, assim como afirma Faria (2008). Ademais, o artigo 232 da mesma lei indica que os indígenas, as comunidades e organizações são partes legítimas para defender seus direitos e interesses, devendo o Ministério Público intervir em todo o processo.

Já o Decreto no 5.051 de 19 de abril de 2004, que incorpora a Convenção 169 da OIT sobre os povos indígenas e tribais, reconhece as aspirações desses povos a assumir o controle de suas formas de vida e desenvolvimento econômico, mantendo e fortalecendo suas identidades, línguas e espiritualidade (BRASIL, 2004).

0 artigo $2^{\circ}$ designa que:

1. Os governos deverão assumir a responsabilidade de desenvolver, com a participação dos povos interessados, uma ação coordenada e sistemática com vistas a proteger os direitos desses povos e a garantir o respeito pela sua integridade. (BRASIL, 2004)

Entre essas ações inerentes aos governos, deve-se incluir medidas que promovam a plena efetividade dos direitos sociais, culturais e econômicos dos povos 
indígenas e tribais, e que contribuam para a eliminação das desigualdades socioeconômicas que possam existir entre os povos indígenas e os não indígenas (BRASIL, 2004).

0 artigo $7^{\circ}$ desse decreto designa que os povos indígenas e tribais têm o direito de escolher suas prioridades no que se refere ao processo de desenvolvimento e controlar, na medida do possível, o seu próprio desenvolvimento econômico, social e cultural.

Outra peça legal a ser considerada no debate sobre o turismo em territórios indígenas é o Decreto no 7.747/2012, que institui a Política Nacional de Gestão Ambiental e Territorial de Terras Indígenas (PNGATI), e tem entre suas diretrizes o "protagonismo e autonomia sociocultural dos povos indígenas, inclusive pelo fortalecimento de suas organizações" (BRASIL, 2012a). Ademais, prevê o apoio às iniciativas indígenas sustentáveis de etnoturismo e ecoturismo, respeitada a decisão da comunidade e a diversidade dos povos indígenas.

Por fim, cabe destacar a Lei no 12.593/2012, que instituiu o Plano Plurianual (PPA) para o período de 2012 a 2015. o PPA é um instrumento de planejamento governamental com objetivo de viabilizar a implementação e a gestão das políticas públicas e auxiliar na promoção do desenvolvimento sustentável. Entre seus objetivos está o de garantir e promover a proteção, recuperação, conservação e uso sustentável dos recursos naturais dessas áreas, além de melhor qualidade de vida e de condições de reprodução física e cultural dos povos indígenas, respeitando sua autonomia. Nisso inclui-se como meta a regulamentação do ecoturismo e etnoturismo em terras indígenas (BRASIL, 2012b).

Com esses instrumentos legais, pode-se perceber que o turismo não foi, em momento algum, proibido. Pelo contrário, algumas propostas de turismo em terras indígenas tinham em seus objetivos a intenção de corroborar com o desenvolvimento da atividade ou com a livre escolha das comunidades sobre seu desenvolvimento econômico. No entanto, assim como ressaltado anteriormente, a ausência de regulamentação relacionava-se à falta de consenso entre governo, comunidades e demais envolvidos sobre a base legal do turismo em territórios indígenas e possíveis impactos negativos oriundos do desenvolvimento dessa atividade, embora a regulamentação também possa mitigar tais efeitos.

Cabe destacar que além desse impasse, referente à incerteza da legislação, outro fator dificulta a formulação de uma política voltada ao turismo em territórios indígenas, conforme lembrado por Faria (2008): as questões indígenas são tratadas, no Brasil, pela Funai, e o turismo (ou ecoturismo, como abordado pela referida autora), de incumbência do Ministério do Meio Ambiente (MMA) e, após 2003, tornou-se responsabilidade do Ministério do Turismo (MTur). Assim, de um lado, a Funai não dispõe de recursos humanos qualificados para tratar do tema, e, do outro, considera-se que o MTur não teria domínio de alguns aspectos importantes para o desenvolvimento dessa atividade em comunidades indígenas.

No entanto, questiona-se: Para quem estaria voltada essa política? Não seria para os indígenas? Então, considera-se que o foco do desenvolvimento de políticas públicas para o turismo em territórios indígenas deve ser a participação comunitária, dando voz aos maiores interessados, beneficiados ou prejudicados pela instauração dessa política, levando em consideração a opinião, as necessidades e os desejos dos povos indígenas, tal qual defende Faria (2008). Desse modo, 
entende-se que os instrumentos legais deveriam estar baseados no modelo de turismo de base comunitária, o qual tem como motivação a superação da lógica capitalista utilitarista materialista tendo por base os princípios de equidade social, prudência ecológica e responsabilidade econômica (FORTUNATO; SILVA, 2013), ou seja, ele não representa um segmento do turismo, mas sim uma alternativa ao turismo de massa. 0 turismo de base comunitária pode ser considerado um instrumento para inclusão social e promoção do desenvolvimento sustentável, com plena participação da população no processo de construção, planejamento e organização da atividade turística (BRANDÃO, 2012).

Mas o que impediria a criação dessa política? Para Brandão (2012, p. 83), o turismo envolvendo comunidades indígenas "não ganhou força menos por falta de iniciativas dos povos indígenas, e mais pela ausência de sensibilidade dos gestores e planejadores das políticas públicas de turismo, que não têm dado o devido apoio, valorização e incentivo à cultura indígena brasileira". Considera-se essa, no entanto, uma ideia incompleta, uma vez que o MTur é apresentado como o único órgão responsável por essa política, ignorando a necessidade de um diálogo institucional e que outros órgãos se fazem importantes, como a Funai, governos estaduais e municipais, organizações não governamentais e associações indígenas.

Lac (2005), por sua vez, aponta que a tutela, desenvolvida com o extinto Serviço de Proteção ao Índio (SPI) e mantida pela Funai, influenciava as outras instâncias governamentais na atuação com os povos indígenas. Ou seja, ainda que seja assegurada pela Constituição Federal (BRASIL, 1988) a autonomia indígena, a tutela seria um entrave para que outros órgãos se mobilizassem em prol da regulamentação do turismo em territórios indígenas.

No que se refere ao exposto acima, Santos (2010) observa que, enquanto o órgão oficial do indigenismo brasileiro, ou seja, a Funai, não se pronunciava, o MMA e o MTur financiaram projetos de turismo de organizações indígenas, retirando, assim, a responsabilidade total dos órgãos de turismo sobre a ausência de regulamentação da atividade.

O MMA foi, provavelmente, o órgão que mais apoiou as iniciativas de turismo em territórios indígenas. Por meio de acordos bilaterais entre países, implantou projetos socioambientais em diferentes linhas temáticas, entre elas o turismo na Amazônia Legal e na Mata Atlântica (LUSTOSA, 2012). Entre os projetos implementados, pode-se citar o Projeto Demonstrativo de Povos Indígenas (PDPI), o Programa de Apoio ao Ecoturismo e à Sustentabilidade Ambiental do Turismo (Proecotur) e a Carteira Indígena (CI), um programa em conjunto com o Ministério do Desenvolvimento Social e Combate à Fome (MDS), conforme menciona a mesma autora.

Isso demonstra, tal qual apontado por Santos (2010) que os povos indígenas apresentam o turismo em suas terras como um projeto inadiável, ou, então, pode-se dizer que apresentam o turismo como um projeto vigente, mas que, por falta de regulamentação, vem ocorrendo por vezes de forma desordenada.

Paralelo a isso, a própria Funai já recebeu várias solicitações das próprias comunidades indígenas, que, em consonância com a política indigenista vigente, reflete as dificuldades que esse órgão enfrenta para estabelecer uma proposta (que não deve se caracterizar como "modelo") para a implantação dessa atividade, respeitando a legislação indigenista e ambiental brasileira 
(SANTOS, 2010). Diante da necessidade de regulamentação da atividade e da incerteza sobre como fazê-lo, algumas medidas legais vêm sinalizando uma flexibilização no debate.

Além dessa, destaca-se outra medida que poderia corroborar com a regulamentação da atividade. A pressão contínua sofrida pela Funai impulsionou a criação de um Grupo de Trabalho sobre Turismo em Terras Indígenas, em 2006 (SANTOS, 2010). Em agosto de 2014, foi instituído um Grupo de Trabalho Interministerial (Portaria Interministerial no 1.372), formado pelo Ministério da Justiça, MTur e pela Funai, com o objetivo de propor medidas e ações para a regulamentação e o desenvolvimento das atividades turísticas em Terras Indígenas a fim de promover a valorização cultural e geração de renda por meio do turismo étnico ou do ecoturismo (BRASIL, 2014). Essas medidas indicam haver avanço no que diz respeito à articulação governamental em prol do desenvolvimento turístico em comunidades que são favoráveis a essa atividade, embora não tenha tido a participação direta das comunidades indígenas.

A ausência da regulamentação ou permissão legal é o fator inibidor de maior apoio por parte da Funai, tal como pode ser visto no estudo de Brandão (2012). Essa pesquisadora, ao entrevistar agentes da Funai (que tiveram sua identidade preservada) constatou que, para eles, sendo as TI áreas da União, tudo que a lei não regulamenta ou não tem regras claras não é possível desenvolver, seguindo, desse modo, uma lógica diferente do que ocorre na área privada, contexto em que o que a lei não proíbe é permitido.

Desse modo, ainda que alguns agentes fossem favoráveis ao turismo (assim como o eram para outras atividades econômicas, como a mineração), não havia regulamentação e, por isso, não havia o devido apoio do órgão indigenista, ainda que o órgão não pudesse impedir o desenvolvimento de tal atividade. No entanto, no ano de 2000, a Funai enviou 47 questionários com o objetivo de levantar dados sobre as iniciativas de ecoturismo em TI. Dezenove questionários foram respondidos e, destes, em treze se informou a existência de visitação na comunidade respondente (CHAVES, 2006). Lac (2005) relata que, no ano de 2004, foi solicitado pela Funai que cada TI enviasse uma carta manifestando sua vontade de implantar ou desenvolver o turismo, para planos posteriores, o que se considera uma demonstração de que tal órgão era consciente da necessidade da regulamentação dessa atividade, bem como das diretrizes para sua implantação.

Além disso, a Funai já vinha apoiando técnica e financeiramente iniciativas de turismo, como é o caso dos Pataxó na Bahia, dos Guarani M’bya em São Paulo e Rio de Janeiro, dos Tenharim no Amazonas e dos Kaxinawá no Acre (FUNAI, 2015a).

No ano de 1997 foi elaborado pelo Grupo Técnico de Coordenação do Ecoturismo para a Amazônia Legal (GTC Amazônia) um intento de organização do turismo em territórios indígenas (OLIVEIRA, 2006). Segundo Oliveira (Ibid.), esse grupo, promovido pelo MMA, com o apoio da Funai e do Instituto Brasileiro de Turismo, publicou o Manual Indígena de Ecoturismo (BRASIL, 1997), naquele mesmo ano, que, teoricamente, deveria servir de base para as ações do Estado, das organizações não governamentais (ONG) e das populações indígenas na organização do turismo. No entanto, assim como ressaltado pelo investigador, a proposta foi construída com pouca participação dos povos indígenas, fato que 
pesou negativamente para a efetivação da proposta. Além disso, pode-se somar o fato de que se propunha o ecoturismo como segmento prioritário para os territórios indígenas, sem levar em consideração as características e o potencial de cada comunidade. Nesse sentido, Oliveira (2006) aponta que o turismo em territórios indígenas que estava ocorrendo no país não poderia ser identificado a partir do conteúdo do manual em questão.

Lustosa (2012) chama atenção para o fato de que a regulamentação da atividade turística em territórios indígenas parece não ter tido grande evolução. Segundo essa pesquisadora, a Funai estava adotando um modelo de turismo que trazia em seu bojo o vício da tutela. Além disso, não considerava as condições étnicas específicas e direcionava projetos-piloto de turismo (no Parque Nacional do Xingu e na TI Coroa Vermelha) padronizados, como se fosse possível replicar a mesma experiência nos diferentes povos indígenas do país e nas diferentes realidades vivenciadas por cada comunidade.

Brandão (2012) verificou que os indígenas participantes de sua investigação gostariam que houvesse regulamentação do turismo e apoio e cooperação do Estado, sendo citado inclusive que os indígenas não queriam depender do governo, mas sim ter autonomia sobre suas próprias vidas. Baggio (2007) analisa que, apesar da tutela ser um obstáculo à autogestão, havia tendência a respeitar cada vez mais a livre decisão sobre seu próprio futuro e sobre o que é feito em seus territórios.

Nesse sentido, cabe destacar algumas iniciativas que ocorreram no Brasil, cada uma com suas peculiaridades e desenvolvidas de modo distinto, algumas delas impostas às comunidades, outras desenvolvidas por elas, algumas benéficas (conforme a própria visão comunitária), outras invasivas. No entanto, os exemplos negativos servem para uma reflexão em torno da importância da regulamentação, a fim de inibir práticas abusivas, ilegais e que gerem apenas impactos nas comunidades visitadas, que são, por vezes, apenas utilizadas como chavão turístico. Acredita-se, assim como apontado por Santos (2010), no entanto, que as organizações políticas indígenas vinham dialogando com o órgão indigenista oficial, não mais pela dinâmica "Funai é que sabe", mas pela imposição do "nós é que sabemos".

\section{A INSTRUÇÃO NORMATIVA No 3/2015}

Embora houvesse mobilização para a regulamentação do turismo em territórios indígenas, destaca-se a importância dessa política ser embasada na sustentabilidade. No entanto, assim como destaca Gallois (2005), a sustentabilidade, bem como a autonomia, deve ser a meta dessa política.

0 pesquisador supracitado defende a necessidade de novas práticas nas políticas públicas, que se embasariam nos princípios de que "conhecer é o primeiro passo para dimensionar a capacidade de sustentação de formas de organização social e política, sistemas de produção, consumo e troca, padrões locais de sustentabilidade" (Ibid., p. 33), bem como verificar, por meio desse conhecimento prévio como "ajudar as comunidades e garantir que suas formas de organização, produção e troca sejam dinamicamente enriquecidas em experiências controladas pelas próprias comunidades" (Loc. cit.). Visando dar apoio a iniciativas 
indígenas sustentáveis no âmbito turístico, após anos de debate, a Funai regulamentou, no dia 11 de junho de 2015, a atividade turística em Terras Indígenas, mais especificamente o turismo de base comunitária e sustentável, por meio dos segmentos de etnoturismo ${ }^{3}$ e ecoturismo ${ }^{4}$ (FUNAI, 2015a; FUNAI, 2015b). Essa regulamentação, que ocorreu por meio da Instrução Normativa no 3/2015, é um dos desdobramentos da PNGATI (FUNAI, 2015b).

Desse modo, o proposto por Gallois (2005) foi, em parte, concretizado, uma vez que a regulamentação da atividade turística em territórios indígenas contribui para a geração de renda, uma das bases da sustentabilidade, ao mesmo tempo em que valoriza as formas de organização social e política nas comunidades.

Para aprovação e publicação de tal Instrução Normativa, a Funai promoveu, em 2014, uma oficina de divulgação, com o objetivo de informar o movimento indígena sobre o tema e aprimorar a minuta do documento (BRASIL, 2014). 0 material discutido em tal oficina, que consequentemente foi base para estruturação do instrumento legal supracitado, é fruto da sistematização das informações coletadas em levantamento bibliográfico, documentos sobre o tema e incursões a diversas comunidades indígenas do país que já desenvolviam o turismo, segundo informado pela Funai (BRASIL, 2014).

Conforme disposto, a Instrução Normativa 3/2015 considera o disposto no Decreto no 5.051/2004, no Decreto no 7.747/2012 e na Lei 12.593/2012, anteriormente abordados, e além da regulamentação da atividade em si, estabelece normas e diretrizes relativas à atividade turística (FUNAI, 2015b). Segundo esse documento legal, são objetivos da visitação turística em territórios indígenas:

A valorização e a promoção da sociodiversidade e da biodiversidade, por meio da interação com os povos indígenas, suas culturas materiais, imateriais e o meio ambiente, visando à geração de renda, respeitando-se a privacidade e a intimidade dos indivíduos, das famílias e dos povos indígenas, nos termos por eles estabelecidos. (FUNAI, 2015b)

Assim, entende-se que a regulamentação ocorreu mediante entendimento de que o turismo seria um importante meio de obtenção de renda para as comunidades indígenas, ao mesmo tempo em que se constituiria uma ferramenta para fortalecimento da etnicidade e divulgação das culturas indígenas.

Para que as atividades turísticas ocorram em consonância com a lei, é preciso que a comunidade interessada proponha um Plano de Visitação, que deverá ser analisado pela Funai (FUNAI, 2015b). Ou seja, é possível que a comunidade não tenha autorização para desenvolver o turismo. Além disso, é preciso enviar à Funai, periodicamente, relatórios sobre as visitações, com informações consolida-

3. O etnoturismo ou turismo étnico sobrepõe-se em um sistema preexistente de relações étnicas entre um grupo dominante e um ou mais grupos marginalizados cujo atrativo turístico é o exotismo de determinado grupo étnico, como, no caso do Brasil, os indígenas, os quilombolas, as comunidades que representam os processos de imigração europeia e asiática e outros grupos que preservam seu legado histórico-cultural e o saber-fazer tradicional (CORBARI; BAHL; SOUZA, 2015).

4. O ecoturismo é uma convergência do turismo de natureza com o turismo cultural e tem um caráter comunitário pautado no planejamento participativo. Esse segmento não deve ser confundido com o turismo ecológico ou com quaisquer atividades turísticas que sejam pautadas no patrimônio natural como atrativo principal, pois aquele é uma junção do ambiente natural e motivações culturais (FARIA, 2005; 2008), embora prevaleça o interesse, por parte do ecoturista, pelo ambiente natural. 
das de todo o período autorizado pelo órgão (FUNAI, 2015b). No entanto, não há nenhum modelo apresentado, nem diretrizes para estabelecê-lo. Isso demonstra que apesar do intuito desse órgão de estimular a autonomia dos povos indígenas no Brasil, ainda há controle do Estado sobre as decisões e atividades realizadas nas TI. Assim, o controle das experiências pelas próprias comunidades, como propõe Gallois (2005) não ocorreria.

Ainda que o turismo tenha sido regulamentado nas TI, os projetos precisarão passar pelo crivo da Funai e poderão, assim, não ser autorizados, o que poderia acarretar no desenvolvimento de projetos mesmo sem aval do Estado. Quanto à prática do turismo sem passar pela avaliação e autorização da Funai, embora não seja permitida, não há cláusulas na lei que indiquem sanções. A Instrução Normativa em questão aponta apenas casos em que a autorização pode ser suspensa ou revogada e informa que "em terras indígenas com presença de índios isolados ou de recente contato, medidas adicionais de proteção poderão ser tomadas" (FUNAI, 2015b, n. p.), embora não constem quais medidas seriam essas. Além disso, as atividades de visitação que já estivessem sendo executadas antes da publicação da Instrução Normativa teriam o prazo de dois anos para se adequarem às regras estabelecidas (FUNAI, 2015b). Destaca-se, novamente, não haver menção a possíveis sanções às comunidades indígenas e, portanto, a prática ilegal poderia seguir existindo.

Conforme o artigo 5ำ da Instrução Normativa, o Plano de Visitação precisa contemplar: objetivos e justificativa da proposta de visitação; público alvo, frequência de visitas previstas, quantidade máxima de pessoas por visita e previsão de duração das visitas; distribuição das competências, levando em consideração os aspectos sociais, geracionais e de gênero; parceiros envolvidos no projeto, bem como suas responsabilidades e atribuições; descrição das atividades propostas ao visitante; delimitação do roteiro, constando mapa ou croqui; condições de transporte, hospedagem, alimentação e atividades correlatas à visitação; plano de negócios simplificado, contendo custos previstos para operação, manutenção e monitoramento da visitação e atividades, bem como previsão de receita, lucro e investimento; estratégia de atendimento de primeiros socorros; manual de conduta e boas práticas para visitantes e para a comunidade; estratégia de impedimento da entrada de bebidas e drogas nas comunidades indígenas e outros produtos ilícitos; estratégia de gestão de resíduos sólidos; estratégia de monitoramento da atividade de visitação; e estratégia de capacitação dos proponentes (FUNAI, 2015b).

Entende-se que esse plano não servirá apenas para que a Funai tenha conhecimento de como o turismo será desenvolvido - e assim possa autorizá-lo ou negá-lo, mas para as próprias comunidades, que poderão analisar os riscos, potencialidades, pontos fracos, oportunidades e se organizarem para a implantação e desenvolvimento do turismo no local. Considera-se o plano um instrumento chave para quaisquer iniciativas de turismo.

Para que os visitantes tenham acesso às TI é preciso apresentar documento de identidade, ou, no caso de estrangeiros, passaporte e documentação comprobatória de regularidade em território brasileiro e autorização individual de ingresso, a ser disponibilizada pelas comunidades no ato de ingresso às TI. Além disso, a Funai poderá exigir carteira de vacinação e atestado médico que comprove que o visitante não é portador de doença infectocontagiosa. Ademais, não será concedida autorização a indivíduos que tenham sido penalizados com revogação ou 
cassação de autorização de ingresso de qualquer modalidade (turística, para pesquisa, jornalística, entre outras) nos últimos cinco anos (FUNAI, 2015b).

Por fim, existe a possibilidade de suspensão ou revogação das autorizações, que irão ocorrer se houver:

I - Violação de direitos dos povos indígenas;

II - Iminência de conflito fundiário ou social na terra indígena;

III - Prejuízo na prestação de serviços públicos;

IV - Situação que importe em risco à vida, à saúde ou à segurança dos visitantes, da comunidade indígena ou de seus parceiros;

V - Existência de procedimento administrativo ou judicial de extrusão de não índios da terra indígena;

VI - Confirmação da presença de índios isolados na área afetada pelo Plano de Visitação;

VII - Ocorrência de ilícitos ambientais relacionados à atividade de visitação;

VIII - Descumprimento de qualquer obrigação prevista no Plano de Visitação aprovado ou na presente Instrução Normativa. (FUNAI, 2015b, n. p.)

Cabe destacar que a responsabilidade pela manutenção da ordem é das comunidades, dos turistas e dos parceiros públicos ou privados, quando houver.

Com isso, assim como ressaltado pela Funai (2015b), espera-se contribuir na estruturação do turismo enquanto alternativa de geração de renda e, ao mesmo tempo, enquanto instrumento de conservação ambiental e valorização cultural. Isso vai ao encontro do proposto por Gallois (2005) quando afirma que, no campo indigenista, as políticas públicas estiveram voltadas ao atendimento de demandas emergentes, embasadas no assistencialismo. Essa Instrução Normativa poderia contribuir para a ruptura com o assistencialismo, embora a expectativa seja que apenas algumas comunidades desenvolvam o turismo, uma vez que nem todas têm interesse na atividade (FUNAI, 2015b).

\section{CONSIDERAÇÕES FINAIS}

O turismo em territórios indígenas, em especial dentro das TI, vinha acontecendo, no Brasil, sem regulamentação. Diversas comunidades das mais variadas etnias recebiam visitantes mesmo sem autorização legal do Estado.

O desenvolvimento do turismo dependia da autorização legal, embora a legislação não proibisse tal prática. Pode-se perceber que diversos instrumentos legais abordam a obrigação do Estado em auxiliar o desenvolvimento econômico segundo as necessidades e aspirações das comunidades indígenas, bem como a busca pelo protagonismo desses povos. No que tange ao turismo, alguns instrumentos legais especificam a importância e necessidade do apoio a essa atividade, como é o caso da Lei no 12.593/2012, que instituiu o PPA de 2012 a 2015 (BRASIL, 2012b).

Percebeu-se que, com o passar do tempo, várias iniciativas foram desenvolvidas em prol do turismo envolvendo comunidades indígenas, inclusive partindo do Governo Federal. No entanto, a falta de consenso sobre os benefícios da regulamentação da atividade, a incerteza sobre a responsabilidade (se do MTur, do MMA ou da Funai) e a falta de recursos humanos qualificados no que 
diz respeito a esse tema, a falta de participação direta dos indígenas nas tomadas de decisões, entre várias outras questões, contribuíram para o atraso na regulamentação da atividade.

Por outro lado, tanto a existência de iniciativas sem autorização legal quanto a pressão sofrida pela Funai para a regulamentação do turismo contribuíram para que o órgão definisse normas e regulamentasse a visitação turística em Terras Indígenas, o que ocorreu em junho de 2015, por meio da Instrução Normativa 3 (FUNAI, 2015b).

Entende-se que a regulamentação do turismo em Terras Indígenas pode gerar efeitos positivos, dado que o instrumento legal serve de base para o planejamento turístico, por meio da qual as comunidades e demais instituições proponentes deverão refletir sobre riscos, impactos, potencial e demais questões relacionadas à atratividade, superestrutura e infraestrutura local. Além disso, a regulamentação do turismo possibilita a ampliação da política de turismo no âmbito das comunidades indígenas, e controle das atividades e das pessoas que ingressam nas TI, possibilitando, quando necessário, a ação governamental para mitigar ou impedir práticas abusivas, seja por parte das comunidades, dos turistas ou de entidades envolvidas, como, por exemplo, projetos em que apenas organizações não indígenas se beneficiem; inibição de práticas ilegais, como tráfico de plantas e animais. Igualmente, a legalização da atividade pode gerar um sentimento de segurança nos indígenas quanto à implantação do turismo, assim, comunidades que não o haviam implantado antes poderão pensá-lo como uma possibilidade de geração de renda e valorização sociocultural.

Não obstante, considera-se que a Normativa contém falhas, principalmente se comparada aos instrumentos legais que a embasaram. Como exemplo tem-se que, embora tenha sido elaborada para colaborar com a autonomia dos povos indígenas, ela não a concede em sua totalidade, uma vez que as comunidades que desejarem se inserir como destino turístico deverão apresentar periodicamente relatórios à Funai e poderão, inclusive, ter a permissão negada.

Assim como informado pela Funai (2015a), não se espera que todas as comunidades se insiram no mercado turístico, uma vez que nem todas desejam ou estão preparadas para receber visitantes. No entanto tem-se, no turismo, a possibilidade de geração de renda, aliada à valorização e divulgação étnico-cultural.

Entende-se que o próximo passo é elaboração de programas de capacitação e qualificação dessas comunidades para atender aos visitantes; incentivo à melhoria da infraestrutura básica e turística; maior participação dos indígenas nas tomadas de decisão, na elaboração e implantação de programas e projetos de turismo em todo país; e, sobretudo, medidas de valorização sociocultural e divulgação étnico-cultural para os não indígenas.

No que se refere à falta de autonomia das comunidades - o que deve ser incentivado inclusive porque o governo brasileiro segue a Convenção 169 da OIT (BRASIL, 2004) -, acredita-se que ela somente será possível quando superados alguns obstáculos legais, como, por exemplo, a tutela do Estado, em que o indígena está subordinado às exigências legais. 0 turismo, enquanto atividade econômica que pode gerar impactos negativos, precisa ser delineado para se fortalecer dentro da política indigenista, mas alinhado à lógica do etnoecodesenvolvimento e baseado no desenvolvimento sustentável. 


\section{REFERÊNCIAS}

BAGGIO, A. J. Ecoturismo: alternativa sustentável de valorização do patrimônio natural e cultural da Terra Indígena Mangueirinha, PR. 2007. 178 f. Dissertação (Mestrado em Ciências Sociais Aplicadas) - Universidade Estadual de Ponta Grossa, Ponta Grossa, 2007. Disponível em: <http://www.dominiopublico.gov.br/ download/texto/cp043493.pdf>. Acesso em: 27 jul. 2015.

BRANDÃO, C. N. Turismo em Terras Indígenas como fator de desenvolvimento local sustentável: estudo de caso nas comunidades indígenas de Roraima. 2012. 158 f. Dissertação (Mestrado em Administração de Empresas) - Fundação Getúlio Vargas, São Paulo, 2012. Disponível em: <http://bibliotecadigital.fgv.br/dspace/bitstream/handle/10438/10293/Disserta\%C3\%A7\%C3\%A3o_Mestrado_Final_Version_2012.pdf?sequence=1>. Acesso em: 27 jul. 2015.

BRASIL. Constituição da República Federativa do Brasil de 1988. Diário Oficial da União, Brasília, DF, 5 out. 1988. Disponível em: <http://www.planalto.gov.br/ccivil_03/constituicao/constituicao.htm>. Acesso em: 4 ago. 2015.

. Decreto $n^{0} 1.775$, de 8 de janeiro de 1996. Dispõe sobre o procedimento administrativo de demarcação das terras indígenas e dá outras providências. Diário Oficial da União, Brasília, DF, 9 jan. 1996. Seção 1, p. 265. Disponível em: <http://www.planalto. gov.br/ccivil_03/decreto/D1775.htm>. Acesso em: 29 jul. 2015.

. Decreto no 5.051, de 19 de abril de 2004. Promulga a Convenção no 169 da Organização Internacional do Trabalho - OIT sobre Povos Indígenas e Tribais. Diário Oficial da União, Brasília, DF, 20 abr. 2004. Seção 1. Disponível em: <http://www.planalto.gov.br/ ccivil_03/_ato2004-2006/2004/decreto/d5051.htm>. Acesso em: 4 ago. 2015.

. Decreto no 7.747, de 5 de junho de 2012. Institui a Política Nacional de Gestão Territorial e Ambiental de Terras Indígenas - PNGATI. Diário Oficial da União, Brasília, DF, 6 jun. 2012a. Seção 1. Disponível em: <http://www.planalto.gov.br/ccivil_03/_ato20112014/2012/decreto/d7747.htm>. Acesso em: 29 jul. 2015.

. Lei no 6.001, de 19 de dezembro de 1973. Dispõe sobre o Estatuto do Índio. Diário Oficial da União, Brasília, DF, 21 dez. 1973. Seção 1. Disponível em: <http://www.planalto.gov.br/ccivil_03/Leis/L6001.htm>. Acesso em: 29 jul. 2015.

. Lei no 12.593 , de 18 de janeiro de 2012. Institui o Plano Plurianual da União para o período de 2012 a 2015. Diário Oficial da União, Brasília, DF, 19 jan. 2012b. Seção 1. Disponível em: <http://www.planalto.gov.br/ccivil_03/_ato2011-2014/2012/Lei/L12593. htm>. Acesso em: 4 ago. 2015.

. Ministério da Justiça. Portaria Interministerial no 1.372, de 18 de agosto de 2014. Institui Grupo de Trabalho Interministerial com a finalidade de propor medidas e ações necessárias para regulamentar e desenvolver as atividades turísticas em terras indígenas. Diário Oficial da União, Brasília, DF, 19 ago. 2014. Seção 1, n. 158, p. 27. Disponível em: <http://www.lex.com.br/legis_25860029_PORTARIA_INTERMINISTERIAL_N_1372_ DE_18_DE_AGOSTO_DE_2014.aspx>. Acesso em: 4 ago. 2015.

. Ministério do Meio Ambiente. Manual indígena de ecoturismo. Brasília: MMA, 1997.

CALEFFI, P. “O que é ser índio hoje?” A questão indígena na América Latina/Brasil no início do Século XXI. Diálogos Latinoamericanos, Aarthus, n. 7, p. 20-42, 2003. Disponível em: <http://bit.ly/2mm3EYZ>. Acesso em: 20 mar. 2017.

CHAVES, R. P. R. 0 turismo étnico em comunidades indígenas no Brasil: a Reserva Pataxó da Jaqueira e o Parque Indígena do Xingu. In: ASENSIO, R. H.; PÉREZ GALÁN, B. (Eds.). ¿El turismo es cosa de pobre? Patrimonio cultural, pueblos indígenas y nuevas formas de turismo en América Latina. Tenerife: ACA, 2012. p. 115-129. (Coleccion PASOS edita, 
n. 4.). Disponível em: <http://www.pasosonline.org/Publicados/pasosoedita/PSEdita8. pdf>. Acesso em: 29 jul. 2015.

СОВО, J. M. Study of the problem of discrimination against indigenous populations. New York: United Nations, 1981. Disponível em: <http://undesadspd.org/IndigenousPeoples/ LibraryDocuments/Mart\%C3\%ADnezCoboStudy.aspx>. Acesso em: 23 jul. 2015.

CORBARI, S. D.; BAHL, M.; SOUZA, S. do R. de. A Semana cultural indígena da comunidade de Tekohá Ocoy, São Miguel do Iguaçu, Paraná (Brasil), como meio de divulgação e valorização sociocultural. In: ANJOS, F. A. dos; ANGELI, N. P.; FONTANA, R. de F. (Org.). Turismo na natureza. Itajaí: Univali, 2015. p. 179-201.

CORBARI, S. D.; GOMES, B. M. A.; BAHL, M. Os povos indígenas e o turismo: um enfoque no estado do Paraná (Brasil). In: SEMINÁRIO DA ASSOCIAÇÃO NACIONAL PESQUISA E PÓS-GRADUAÇÃO EM TURISMO, 10., 2013, Caxias do Sul. Anais... São Paulo: Aleph, 2013. Disponível em: <http://www.anptur.org.br/novo_portal/admin/portal_anpur/anais/ arquivos/pdf/[84]x_anptur_2013.pdf>. Acesso em: 26 jul. 2015.

DIEGUES, A. C. S. O mito moderno da natureza intocada. 3. ed. São Paulo: Hucitec, 2001.

FARIA, I. F. de. Ecoturismo: etnodesenvolvimento e inclusão social no Amazonas. Pasos Online, Tenerife, v. 3, n. 1, p. 63-77, 2005. Disponível em: <http://www.pasosonline.org/ Publicados/3105/PS040105.pdf>. Acesso em: 28 jul. 2015.

Ecoturismo indígena: território, sustentabilidade, multiculturalismo: princípios para a autonomia. 2008. $204 \mathrm{f}$. Tese (Doutorado em Geografia Física) - Universidade de São Paulo, São Paulo, 2008. Disponível em: <http://www.teses.usp.br/teses/disponiveis/8/8135/tde-17022011-095412/pt-br.php>. Acesso em: 27 jul. 2015.

FORTUNATO, R. A.; SILVA, L. S. Os conflitos em torno do Turismo Comunitário na Prainha do Canto Verde (CE). Revista Brasileira de Ecoturismo, São Paulo, v. 6, n. 1, p. 123-138, 2013. Disponível em: <http://www.sbecotur.org.br/rbecotur/seer/index.php/ecoturismo/article/view/481/41>. Acesso em: 29 jul. 2015.

FUNAI - FUNDAÇÃO NACIONAL DO ÍNDIO. FUNAI normatiza Etno e Ecoturismo em Terras Indígenas. 8 jul. 2015a. Disponível em: <http://www.funai.gov.br/index.php/comunicacao/noticias/3334-funai-normatiza-etno-e-ecoturismo-em-terras-indigenas>. Acesso em: 4 ago. 2015.

. Instrução Normativa no 3, de 11 de junho de 2015. Estabelece normas e diretrizes relativas às atividades de visitação para fins turísticos em terras indígenas. Diário Oficial da União, Brasília, DF, 12 jun. 2015b. Seção 1, n. 110, p. 41-43. Disponível em: $<$ http://pesquisa.in.gov.br/imprensa/jsp/visualiza/index.jsp?jornal=1\&pagina=41\&data $=12 / 06 / 2015>$. Acesso em: 4 ago. 2015.

GALLOIS, D. T. Cultura "indígena" e sustentabilidade: alguns desafios. Tellus, Campo Grande, v. 5, n. 8/9, p. 29-36, 2005. Disponível em: <http://www.tellus.ucdb.br/index. php/tellus/article/view/93>. Acesso em: 24 maio 2016.

. Terras ocupadas? Territórios? Territorialidades? In: FANY, R. (Org.). Terras indígenas e unidades de conservação da natureza. São Paulo: Instituto Socioambiental, 2004. p. 37-41. Disponível em: <http://pib.socioambiental.org/files /file/PIB_institucional/ dgallois-1.pdf $>$. Acesso em: 29 jul. 2015.

GRÜNEWALD, R. A. Os "índios do descobrimento": tradição e turismo. 1999. 350 f. Tese (Doutorado em Antropologia Social) - Universidade Federal do Rio de Janeiro, Rio de Janeiro, 1999. Disponível em: <http://indiosnonordeste.com.br/wpcontent/uploads/2012/08/TESE-SOBRE-OS-PATAX\%C3\%93-BAHIA.pdf>. Acesso em: 27 jul. 2015.

GUIMARÃES, R. G. Turismo em terras indígenas já é fato: quem se arrisca. Revista Dialogando no Turismo, Rosana, v. 1, n. 1, p. 15-42, 2006. Disponível em: <http://www.rosana. unesp.br/revista/documentos/v1n1a2.pdf>. Acesso em: 27 jul. 2015. 
JESUS, D. J. de. A (re)tradicionalização dos territórios indígenas pelo turismo: um estudo comparativo entre os Kadiwéu (Mato Grosso do Sul - BR) e Maori (Ilha Norte NZ). 2012. 265 f. Tese (Doutorado em Geografia) - Universidade Federal do Paraná, Curitiba, 2012. Disponível em: <http://dspace.c3sl.ufpr.br/dspace/bitstream/handle/1884/27396/R\%20-\%20T\%20-\%20JESUS,\%20DJANIRES\%20LAGEANO\%20DE. pdf?sequence=1>. Acesso em: 27 jul. 2015.

LAC, F. $O$ turismo e os Kaingang na Terra Indígena de Iraí/RS. 2005. 163 f. Dissertação (Mestrado em Antropologia Social) - Universidade Federal do Paraná, Curitiba, 2005. Disponível em: <http://www.dominiopublico.gov.br/download/texto/cp029037.pdf>. Acesso em 27 jul. 2015.

LACERDA, M. A. Perspectivas de desenvolvimento local entre os Terena, na Aldeia Urbana Marçal de Souza, em Campo Grande - MS: a opção pelo etnoturismo. 2004. 158 f. Dissertação (Mestrado em Desenvolvimento Local) - Universidade Católica Dom Bosco, Campo Grande, 2004. Disponível em: <http://site.ucdb.br/public/md-dissertacoes/7946-perspectivas-de-desenvolvimento-local-entre-os-terena-na-aldeia-urbana-marcal-de-souza-em-campo-grande-ms-a-opcao-pelo-etnoturismo.pdf>. Acesso em: 27 jul. 2015.

LUCIANO, G. dos S. O Índio Brasileiro: o que você precisa saber sobre os povos indígenas no Brasil de hoje. Brasília, DF: Ministério da Educação, 2006.

LUSTOSA, I. M. C. Os povos indígenas, o turismo e o território: um olhar sobre os Tremembé e os Jenipapo-Kanindé do Ceará. 2012. 281 f. Tese (Doutorado em Geografia) - Universidade Federal de Goiás, Goiânia, 2012. Disponível em: <http://www.academicoo.com/ artigo/os-povos-indigenas-o-turismo-e-o-territorio-um-olharsobre-os-tremembe-e-os-jenipapo-kaninde-do-ceara/>. Acesso em: 27 jul. 2015.

NEVES, S. C. A apropriação indígena do turismo: os Pataxós de Coroa Vermelha e a expressão da tradição. 2012. 213 f. Tese (Doutorado em Antropologia) - Faculdade de Filosofia e Ciências Humanas, Universidade Federal da Bahia, Salvador, 2012.

NUNES, R. G. A. O turismo como prática social em território indígena: uma análise comparativa entre a Reserva Indígena de Dourados - MS e a aldeia Puiwa Poho em Feliz Natal - MT. 2006. Dissertação (Mestrado em Geografia) - Universidade Federal de Mato Grosso do Sul, Aquidauana, 2006. Disponível em: <http://livros01.livrosgratis.com.br/ cp120114.pdf>. Acesso em: 29 jul. 2015.

OLIVEIRA, V. M. de. Turismo, território e modernidade: um estudo da população indígena Krahô, estado do Tocantins (Amazônia Legal Brasileira). 2006. 207 f. Tese (Doutorado em Geografia Humana) - Faculdade de Filosofia, Letras e Ciências Humanas, Universidade de São Paulo, São Paulo, 2006. Disponível em: <http://www.teses.usp.br/teses/ disponiveis/8/8136/tde-04062007-160917/pt-br.php>. Acesso em: 27 jul. 2015.

OIT - ORGANIZAÇÃO INTERNACIONAL DO TRABALHO. Convenção no 169 sobre povos indígenas e tribais e Resolução referente à ação da OIT. Brasília, DF, 1989. Disponível em: <http://portal.iphan.gov.br/baixaFcdAnexo.do?id=3764>. Acesso em: 25 jul. 2015.

ONU - ORGANIZAÇÃO DAS NAÇÕES UNIDAS. Actividades normativas: evolución de las normas relativas a los derechos de los pueblos indígenas: documento de trabajo sobre el concepto de "pueblos indígenas". Geneva, 1996. Disponível em: <http://daccess-dds-ny. un.org/doc/UNDOC/GEN/G96/129/83/PDF/G9612983.pdf?OpenElement>. Acesso em: 28 jul. 2015.

PÉREZ GALÁN, B.; ASENSIO, R. H. Introducción. In: ASENSIO, R. H.; PÉREZ GALÁN, B. (Eds.). ¿El turismo es cosa de pobre? Patrimonio cultural, pueblos indígenas y nuevas formas de turismo en América Latina. Tenerife: ACA, 2012. p. 15-33. (Coleccion PASOS edita, n. 4). Disponível em: <http://www.pasosonline.org/Publicados/pasosoedita/PSEdita8.pdf >. Acesso em: 29 jul. 2015.

RIBEIRO, D. Línguas e culturas indígenas do Brasil. Rio de Janeiro: Centro Brasileiro de Pesquisas Educacionais, 1957. 
RYAN, C. Tourism and cultural proximity: examples from New Zealand. Annals of Tourism Research, Amsterdam, v. 29, n. 4, p. 952-971, 2002.

RYAN, C.; HUYTON, J. Tourists and aboriginal people. Annals of Tourism Research, Amsterdam, v. 29, n. 3, p. 631-647, 2002.

SANTOS, L. C. Sahu-Apé e o turismo em Terras e comunidades indígenas. 2010. 255 f. Dissertação (Mestrado em Antropologia Social) - Universidade Federal do Amazonas, Manaus, 2010. Disponível em: <http://www.ppgas.ufam.edu.br/attachments/article/31/ Disserta\%C3\%A7\%C3\%A3o\%20-\%20Luciano\%20Cardenes\%20-\%20Sahu-Ap\%C3\%A9.pdf>. Acesso em: 29 jul. 2015.

VAN DEN BERGHE, P. L.; KEYES, C. F. Introduction: tourism and re-created ethnicity. Annals of Tourism Research, Amsterdam, v. 11, n. 3, p. 343-352, 1984. Disponível em: <http://www.sciencedirect.com/science/article/pii/0160738384900264>. Acesso em: 29 jul. 2015.

Recebido em: 27/07/2016

Aprovado em: 29/01/2017 